\title{
Fatigue crack growth behaviour of wire and arc additively manufactured ER70S-6 low carbon steel components
}

\author{
Anna Ermakova • Ali Mehmanparast (i) • \\ Supriyo Ganguly • Javad Razavi · Filippo Berto
}

Received: 1 December 2020 / Accepted: 23 April 2021 / Published online: 24 May 2021

(C) The Author(s) 2021

\begin{abstract}
The new emerging Wire and Arc Additive Manufacturing (WAAM) technology has significant potential to improve material design and efficiency for structural components as well as reducing manufacturing costs. Due to repeated and periodic melting, solidification and reheating of the layers, the WAAM deposition technique results in some elastic, plastic and viscous deformations that can affect material degradation and crack propagation behaviour in additively manufactured components. Therefore, it is crucial to characterise the cracking behaviour in WAAM built components for structural design and integrity assessment purposes. In this work, fatigue crack growth tests have been conducted on compact tension specimens extracted from ER70S-6 steel WAAM built components. The crack propagation behaviour of the specimens extracted with different orientations (i.e. horizontal and vertical with respect to the deposition direction) has been characterised under two different cyclic load levels. The obtained fatigue crack growth rate data have been correlated with the linear elastic fracture mechan-
\end{abstract}

A. Ermakova · A. Mehmanparast $(\varangle)$

Offshore Renewable Energy Engineering Centre, Cranfield

University, England, UK

e-mail: a.mehmanparast@ cranfield.ac.uk

S. Ganguly

Welding Engineering and Laser Processing Centre,

Cranfield University, Cranfield MK43 0AL, UK

J. Razavi · F. Berto

Norwegian University of Science and Technology (NTNU), Trondheim, Norway ics parameter $\Delta K$ and the results are compared with the literature data available for corresponding wrought structural steels and the recommended fatigue crack growth trends in the BS7910 standard. The obtained results have been found to fall below the recommended trends in the BS7910 standard and above the data points obtained from S355 wrought material. The obtained fatigue growth trends and Paris law constants from this study contribute to the overall understanding of the design requirements for the new optimised functionally graded structures fabricated using the WAAM technique.

Keywords Fatigue Crack growth - Structural integrity · WAAM · Additive manufacturing

\section{Nomenclature}

$a_{0} \quad$ Initial crack length in $\mathrm{C}(\mathrm{T})$ specimen

$a_{i} \quad$ Instantaneous crack length

$a_{i, p} \quad$ Crack length after pre-fatigue cracking

$a_{f, c} \quad$ Final crack length (compliance data)

$a_{f, o p} \quad$ Final crack length (fracture surface)

$B \quad$ Total thickness of C(T) specimen

C Material constant for fatigue crack growth

da/dN Fatigue crack growth rate

$H \quad$ C(T) specimen height

$K_{\max } \quad$ Stress intensity factor corresponding to $P_{\max }$

$\Delta K \quad$ Stress intensity factor range 


$\begin{array}{ll}m & \text { Material constant for fatigue crack growth } \\ P_{\max } & \text { Maximum load } \\ R & \text { Load ratio } \\ W & \text { C(T) specimen width } \\ \text { AM } & \text { Additive Manufacturing } \\ \text { B } & \text { Bottom } \\ \text { C(T) } & \text { Compact Tension specimen } \\ \text { CMT } & \text { Cold Metal Transfer } \\ \text { EDM } & \text { Electrical Discharge Machining } \\ \text { FCG } & \text { Fatigue Crack Growth } \\ \text { HAZ } & \text { Heat Affected Zone } \\ \text { H } & \text { Horizontal } \\ \text { SD } & \text { Standard Deviation } \\ \text { SEN(B) } & \text { Single Edge Notched Bend } \\ \text { SEM } & \text { Scanning Electron Microscope } \\ \text { SIF } & \text { Stress Intensity Factor } \\ \text { T } & \text { Top } \\ \text { V } & \text { Vertical } \\ \text { WAAM } & \text { Wire and Arc Additive Manufacturing }\end{array}$

\section{Introduction}

The wire and arc additive manufacturing (WAAM) method creates multi-layer components by melting a wire at a controlled rate using an electric or plasma arc (Williams et al. 2015; Martina et al. 2012). Compared with powder-based additive manufacturing techniques, WAAM has a key advantage of a relatively high deposition rate, depositing several kilograms of metal per hour, resulting in lower cost and reasonably short fabrication time (Brandl et al. 2010; Wang et al. 2011). Additionally, using wire as the feeding material brings fewer safety issues compared to powders (Martina et al. 2012; Zhang et al. 2017a). However, as-deposited WAAM parts may require post processing due to surface roughness and inaccuracies involved in exact dimensions (Greitemeier et al. 2016; Pegues et al. 2018). This technique has already been adopted by the aerospace industry and is now finding its applications in other industrial sectors (Ding et al. 2015). One of the major constraints for the widespread application of WAAM in industries is limited knowledge of the mechanical properties of such components, particularly the fatigue behaviour under different loading and environmental conditions, which is a key requirement for further product design and certification. Moreover, previous studies have shown that the additive manufacturing process, due to repeated melting, solidification and reheating, introduces changes to the microstructure and residual stresses that would have an impact on mechanical and fatigue properties, hence these have to be examined carefully for a more accurate interpretation of the WAAM built components.

The majority of the published work on WAAM built components reported in the literature is on the parts made of titanium and stainless steel alloys, particularly for application in the aerospace industry; however, there is an essential need to examine the fatigue and fracture behaviour of other WAAM built materials, e.g. ferritic steel, to explore the suitability of this AM technology for other high production rate industries such as offshore wind. Experimental evaluation of the fatigue behaviour of WAAM titanium alloy compact tension, C(T), samples by Zhang et al. (2017a, b) revealed considerably lower fatigue crack growth (FCG) rates of the WAAM material compared to the wrought counterpart. Therefore, the WAAM technique was recommended as a strong candidate for manufacturing damage tolerance driven designs. Moreover, different sample orientations were investigated by Zhang et al. (2017a, b) and it was found that the FCG rate is slightly faster when the crack propagates across the WAAM layers, compared to the crack that propagates along the layers. Similar results were reported by Zhang et al. (2016). Gordon et al. (2018) performed FCG tests on 304L stainless steel WAAM built SEN(B) specimens and observed favourable behaviour in the Paris region compared to the conventional wrought stainless steel. It was also reported that as-built parts offer higher FCG resistance. Further observed in their study was some degree of variability in the crack growth rates of different sample orientations, with the lowest rates observed in samples with multi-layer crack paths. 17-4 PH stainless steel WAAM built $\mathrm{C}(\mathrm{T})$ specimens were tested by Nezhadfar (2019) and the results showed lower FCG rates compared to the specimens made of the wrought material.

The preliminary test results reported in the literature on titanium and stainless steel WAAM components show that relatively lower FCG rates were observed in the multi-layer deposited specimens compared to the conventional parts made from the wrought material. However, there is generally limited experimental data available on FCG behaviour of the WAAM built components for a wide range of materials. Therefore, further experimental studies are needed to inform decisions for material selection in the fabrication of future WAAM built components based on the fatigue resis- 
Table 1 Chemical composition of ER70S-6 material (wt.-\%) ${ }^{15}$

\begin{tabular}{|c|c|c|c|c|c|c|c|c|c|c|}
\hline & $\mathrm{C}$ & $\mathrm{Mn}$ & $\mathrm{Cr}$ & $\mathrm{Si}$ & $\mathrm{Ni}$ & Mo & $\mathrm{S}$ & $\mathrm{P}$ & $\mathrm{Cu}$ & $\mathrm{V}$ \\
\hline ER70S-6 & 0.09 & $<1.60$ & 0.05 & 0.09 & 0.05 & 0.05 & 0.007 & 0.007 & 0.20 & 0.05 \\
\hline
\end{tabular}

tance observed in fatigue crack growth tests. To fill this gap in the knowledge, the present study examines the FCG behaviour of WAAM built specimens made with ER70S-6 mild steel wire. Also included in this study is the sensitivity analysis of the fatigue response to the built orientation and applied cyclic load level. The manufacturing process of the WAAM walls, specimen extraction strategy, experimental set-up and the results obtained from the FCG test are presented below, along with discussions and comparison with the existing data in the literature. The results presented in this study provide an insight into the extension of the application of WAAM technology to other industries, such as offshore wind, where a significant number of large scale components must be fabricated within limited timeframes.

\section{Material selection and specimen extraction}

The material used in this study is ER70S-6 copper coated carbon steel welding wire. It is suitable for automatic welding and is well-known for excellent welding properties, stable arc, high deposition efficiency and low spatter. Typical applications for this wire are in the repair of a variety of mild and low alloy steels, small diameter pipes and tubing, sheet metal applications, and root pass pipe welding (Mild Steel Welding Alloy ER70S-6). A moderate amount of rust is acceptable during the welding process which makes this wire a preferable choice for marine applications (ER70S-6 - Weld Wire). However, some post-processing is usually required subsequent to fabrication to remove the generated silicon island deposits. In this study, Lincoln electric ER70S-6 wire (Lincoln Electric Company) was used with the chemical composition summarised in Table 1.

Two additively manufactured walls were built using the Cold Metal Transfer (CMT) based WAAM process, with the manufacturing parameters shown in Table 2. In order to minimise the structural variability of different walls, all the parameters were kept constant during the fabrication process. The manufacturing set-up and an example of the completed wall are displayed in Fig. 1.
Table 2 CMT-WAAM fabrication parameters

\begin{tabular}{ll}
\hline Shielding gas & $\mathrm{Ar}+20 \% \mathrm{CO}_{2}$ \\
Gas flow rate & $15 \mathrm{~L} / \mathrm{min}$ \\
Wire diameter & $1.2 \mathrm{~mm}$ \\
Robot travelling speed & $7.33 \mathrm{~mm} / \mathrm{s}$ \\
Wire feed speed & $7.5 \mathrm{~m} / \mathrm{min}$ \\
Dwell time & $120 \mathrm{sec}$ \\
\hline
\end{tabular}

As shown in the figure, the WAAM set-up consists of the CMT power source, a robot arm with the torch feeding the wire and a simultaneous shielding gas supply. An exhaust fan was also used to draw off the generated fumes and heat from the wall.

Each WAAM wall was built in the middle of the base plate that was made of EN10025 rolled structural steel with the plate dimensions of $420 \times 200 \times 12 \mathrm{~mm}^{3}$. The base plate was fixed on the working table using eight clamps (two for each corner). The clamps helped to prevent the plate from bending due to the thermal energy input, and were released once the completed WAAM wall cooled down to the ambient temperature. Additive layers were deposited on top of each other using an oscillation pattern, the details of which can be found in the work by Ermakova et al. (2019), to create relatively thick walls of approximately $24 \mathrm{~mm}$ in thickness (Y-direction in Fig. 1b), $355 \mathrm{~mm}$ in length (X-direction) and $140 \mathrm{~mm}$ in height (Z-direction).

Once the fabrication of the WAAM walls was completed, test specimens were extracted from each wall using the Electrical Discharge Machining (EDM) technique. Twelve stepped notched compact tension, C(T), specimens were extracted along two different orientations: vertical (V)—with the crack plane perpendicular to the deposited layers, and horizontal $(\mathrm{H})$ - with the crack plane parallel to the deposited layers. As schematically shown in Fig. 2, the specimens denoted CT-V-1 and CT-V-2 are vertically oriented, whereas CT-H-1 and CT-H-2 have horizontal orientation. The $\mathrm{C}(\mathrm{T})$ specimens were extracted in accordance with ASTM E647 (ASTM E647-13 2014) standard with the 
(a)

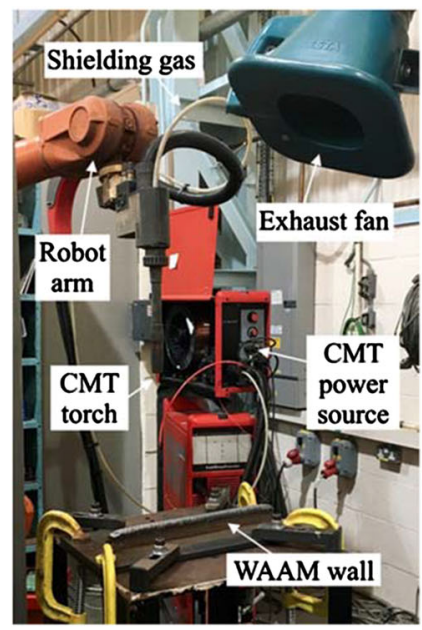

(b)

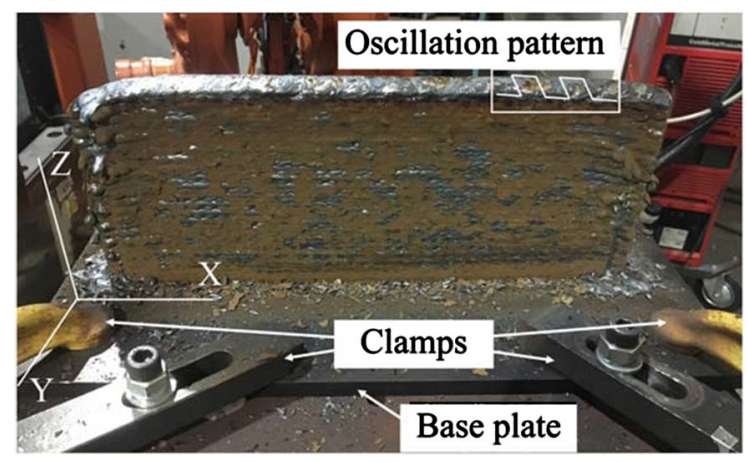

Fig. 1 The fabrication process: a CMT WAAM set-up, b completed wall

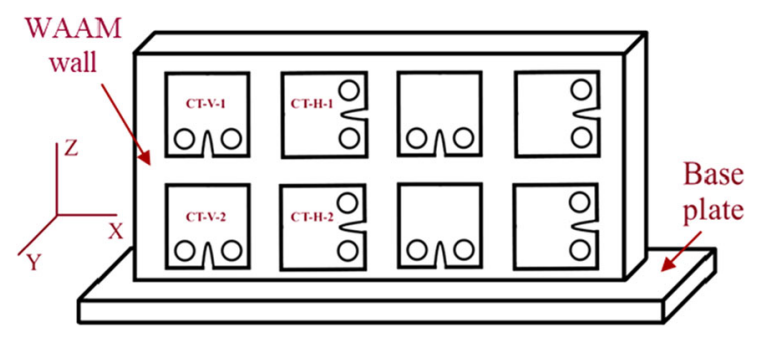

Fig. 2 A schematic demonstration of the specimen extraction plan

width of $W=50 \mathrm{~mm}$, the height of $H=60 \mathrm{~mm}$, total thickness of $B=16 \mathrm{~mm}$ and initial crack length of $a_{0}=17 \mathrm{~mm}$ before pre-fatigue cracking. Also, in order to enable compliance measurements for crack growth monitoring during FCG tests, knife edges were machined at the crack mouth following the instructions provided in E1820 (American Society for Testing and
Materials 2011) to accommodate a clip gauge for compliance measurements throughout the tests.

\section{Fatigue crack growth test set-up and data analysis}

FCG tests were conducted on a $100 \mathrm{kN}$ servo-hydraulic machine under Mode I fracture mechanics loading conditions in accordance with the ASTM E647 (ASTM E647-13 2014) standard. All tests were performed under load control mode at room temperature in air and with the load ratio of $R=0.1$. The fatigue load cycles were applied using a constant amplitude sinusoidal cyclic waveform at $5 \mathrm{~Hz}$ frequency. Six specimens were tested with the maximum applied load of $P_{\max }=10 \mathrm{kN}$, with another six samples tested under $P_{\max }=11 \mathrm{kN}$. For each of the load levels examined in this study, half of the specimens (i.e. three $\mathrm{C}(\mathrm{T})$ specimens) were selected with vertical orientation and the other half with horizontal orientation, to examine crack path effects with respect to the deposited layers in the WAAM walls on the FCG behaviour of the material. Prior to testing, all specimens were pre-cracked under fatigue loading conditions using the load decreasing approach to approximately $20 \mathrm{~mm}\left(a_{i, p} / W=0.4\right)$, to introduce an infinitely sharp crack tip ahead of the machined notch. During the pre-cracking process, it was ensured that the final value of maximum stress intensity factor $K_{\max }$ did not exceed the initial $K_{\max }$ at the beginning of the actual FCG test.

The estimated values of crack length during the precracking phase and the main FCG tests were monitored using the unloading compliance technique (Ermakova et al. 2020), by attaching a clip gauge onto the crack mouth of the specimen. The crack path was carefully observed using high resolution cameras located in front of and behind the test specimens to ensure that the crack propagated straight without any major deviation from the symmetry line in the $\mathrm{C}(\mathrm{T})$ test specimens. Moreover, the cameras were used to cross-check the crack growth readings obtained from the compliance technique by measuring the crack lengths at the outer surface of the $\mathrm{C}(\mathrm{T})$ specimens. The tests were terminated once the crack length, estimated using the compliance technique, reached approximately $35 \mathrm{~mm}$ $\left(a_{f, c} / W=0.7\right)$. The fatigue test set-up and the crack growth monitoring tool employed in this study are presented in Fig. 3. 


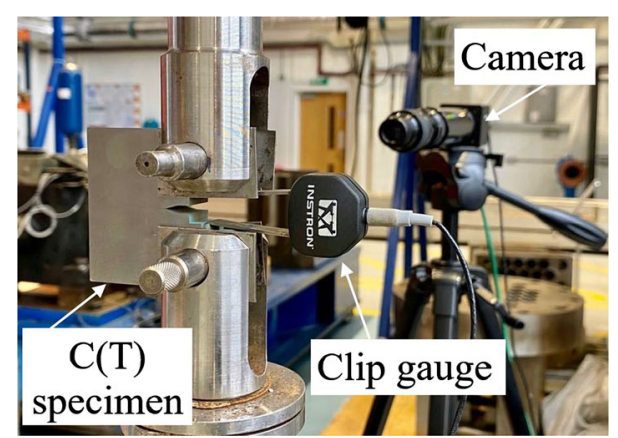

Fig. 3 Fatigue crack growth test set-up

The instantaneous crack length and number of cycles were continuously recorded throughout the tests. The FCG rate, $d a / d N$, was then calculated using the secant method for the first and the last three data points, and the seven-point incremental polynomial technique for the rest of the data points. As suggested by ASTM E647, the stress intensity factor (SIF) range, $\Delta K$, for $\mathrm{C}(\mathrm{T})$ specimen geometry can be obtained using Eq. 1:

$$
\begin{aligned}
\Delta K= & \frac{\Delta P}{B \sqrt{W}} \Delta \frac{(2+\alpha)}{(1-\alpha)^{\frac{3}{2}}} \Delta(0.886+4.64 \alpha \\
& \left.-13.32 \alpha^{2}-14.72 \alpha^{3}-5.6 \alpha^{4}\right)
\end{aligned}
$$

where $\Delta P$ is the applied cyclic load range, and $\alpha=$ $a / W$ is the normalised crack length

However, due to the validity limitation of this equation for $\mathrm{C}(\mathrm{T})$ specimens with shallow crack lengths, a new shape function equation was developed based on numerical analysis in a previous study by Mehmanparast et al. (2017) and incorporated in the calculation of the SIF for $\mathrm{C}(\mathrm{T})$ specimens, which is shown in Eq. 2. It was reported by Mehmanparast et al. (2017) that $\Delta K$ values obtained using Eq. 2 are more accurate for a wider range of normalised crack lengths ranging from $a / W=0.2$ to $a / W=0.7$.

$$
\begin{aligned}
\Delta K= & \frac{\Delta P}{B \sqrt{W}} \Delta \frac{(2+\alpha)}{(1-\alpha)^{\frac{3}{2}}} \Delta \\
& \times\left(-372.12 \alpha^{6}+1628.60 \alpha^{5}-2107.46 \alpha^{4}\right. \\
& \left.+1304.65 \alpha^{3}-391.20 \alpha^{2}+54.81 \alpha+7.57\right)
\end{aligned}
$$

\section{Fatigue crack growth test results and discussion}

The FCG test data, which include the instantaneous crack lengths $a$ and number of cycles, collected dur- ing the tests on all specimens are presented and compared with each other in Fig. 4. As seen in this figure, the initial crack length (after pre-cracking) for all FCG tests was approximately $20 \mathrm{~mm}$, with the exception of two specimens CT-V-1 and CT-V-2 that were precracked to slightly higher values, resulting in shorter FCG test durations in these two test specimens. The comparison of the crack growth trends observed in specimens tested under different loading conditions shows that by increasing $P_{\max }$ from 10 to $11 \mathrm{kN}$, the test duration decreased by approximately 2.3 times for horizontal specimens and 1.5 times for vertical specimens. The results show that under $P_{\max }=10 \mathrm{kN}$, on average around a twice longer fatigue life is generally observed in horizontal specimens, compared to vertical specimens. However, when the applied load level was increased to $P_{\max }=11 \mathrm{kN}$ an opposite trend is observed with the vertical specimens having on average around a 1.3 times longer fatigue life compared to horizontal samples. This trend can be caused due to the microstructural effects, which are discussed next, or induced residual stresses that need to be examined in future work. Finally seen in Fig. 4 is that while the short-term repeat tests under $P_{\max }=11 \mathrm{kN}$ exhibit similar trends with a relatively small level of scatter, the deviation in the test results enlarges in longer-term tests under $P_{\text {max }}=10 \mathrm{kN}$, particularly in the horizontal specimens. This indicates that the fatigue test duration and the level of scatter in the test data strongly depends on the applied load level in the tests on ER70S6 WAAM built specimens.

The FCG rates, $d a / d N$, obtained from the tests on $\mathrm{C}(\mathrm{T})$ specimens have been correlated with the linear elastic fracture mechanics parameter, $\Delta K$, and the results are presented in Fig. 5. It can be seen in this figure that, for a given loading condition, the experimental data obtained from the tests on each specimen orientation fall upon each other, showing four distinct clouds of data and indicating good repeatability for each of the four datasets at two different load levels and on two different specimen orientations. It can be seen in this figure that the FCG results show a higher trend in the tests performed at $P_{\max }=11 \mathrm{kN}$, particularly at greater values of $\Delta K$ towards the end of the tests. The comparison of the results obtained from different orientations shows that under the cyclic applied load of $P_{\max }=10 \mathrm{kN}$ the vertical specimens exhibit a higher FCG rate compared to the horizontal specimens throughout the tests, including the near threshold region and the Paris region. 
Fig. 4 Fatigue crack growth trends in the tests on ER70S-6 WAAM built specimens with different orientations under different applied load levels

Fig. 5 Analysis of the fatigue crack growth rates in ER70S-6 WAAM built specimens with different orientations under different applied load levels
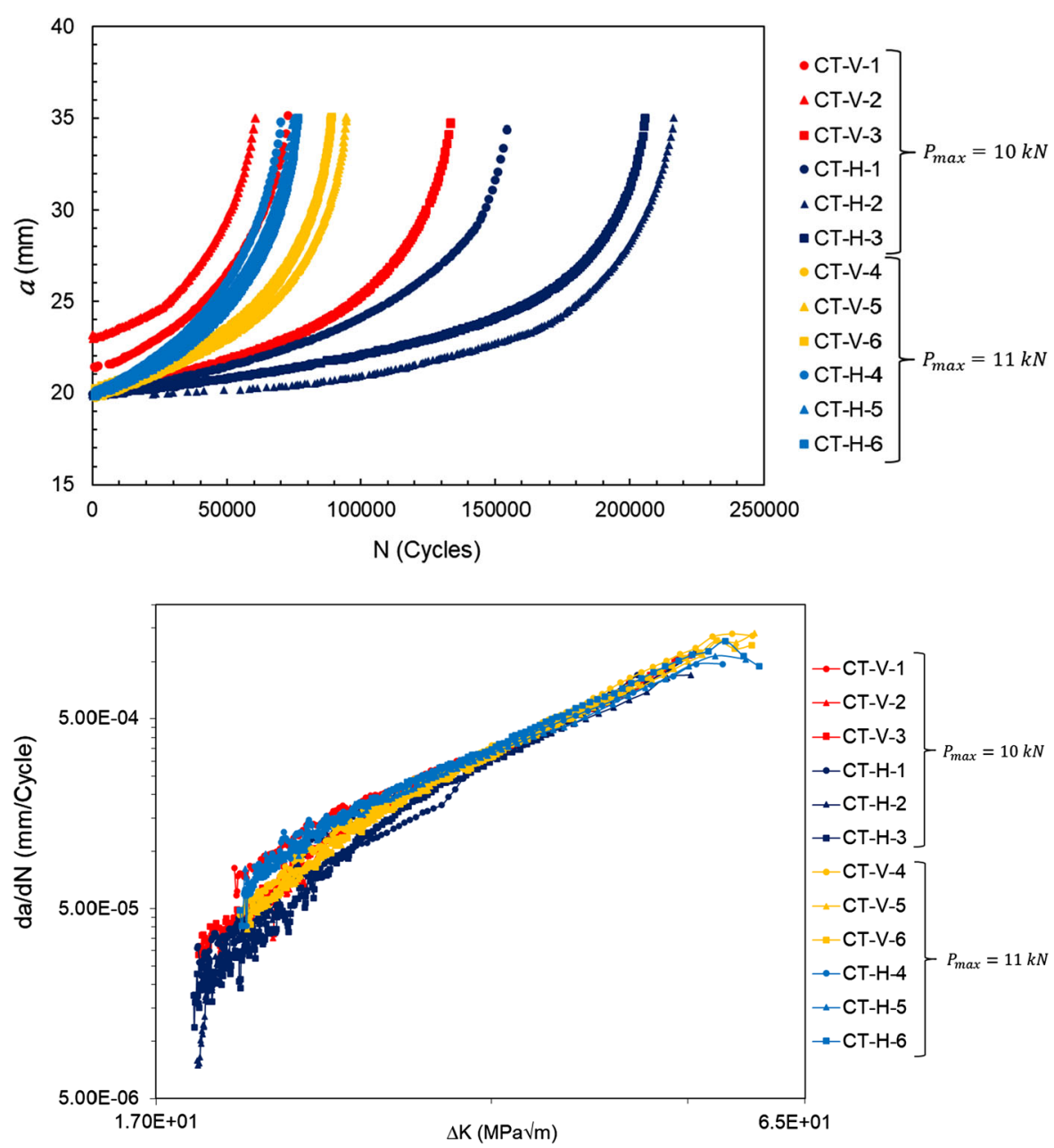

For the tests performed under $P_{\max }=11 \mathrm{kN}$, it can be seen that while the horizontal specimens demonstrate a higher FCG rate in the near threshold region at low values of $\Delta K$, this trend switches for larger crack lengths with the vertical specimens showing a higher FCG rate towards the end of the Paris region. Comparing the experimental clouds in Fig. 5 it can be seen that the lowest FCG rates are observed in horizontal specimens tested under $P_{\max }=10 \mathrm{kN}$.

For each FCG dataset presented in Fig. 5, the material constants $C$ and $m$ in the Paris region with intermediate values of $\Delta K$ (Eq. 3) were obtained by plotting the line of best fit to the data and determining the power-law constants, which are summarised in Table 3. Also included in Table 3 are the values of the coefficient of determination, $R^{2}$, which have been found to be close to 1 , indicating that the lines of best fit, made to the data, accurately describe the realistic behaviour of the material. It can be seen in this table that the values of the stress intensity factor range exponent, $m$, are within the established range of 2 to 4 , which is typically observed in the FCG tests on wrought materials in the absence of a corrosive environment (Anderson 2005). The information on the extraction location of each $\mathrm{C}(\mathrm{T})$ specimen with respect to the height (i.e. top (T) and bottom (B) regions) of the WAAM walls (see Fig. 2) is also reported in Table 3. Comparing the test results in Fig. 5 and Table 3, it was concluded that the extraction location of the $\mathrm{C}(\mathrm{T})$ specimen does not have any major impact on the FCG behaviour of the ER70S-6 steel WAAM specimens, and within the inherent experimental scatter the $d a / d N$ vs. $\Delta K$ trends from specimens extracted at the top and bottom of the WAAM walls fall close to or upon each other.

$d a / d N=C \Delta K^{m}$ 
Table 3 Paris law constants for the fatigue crack growth tests on ER70S-6 WAAM built specimens

\begin{tabular}{lllllll}
\hline Specimen ID & Orientation & Location & $P_{\max }(\mathrm{kN})$ & $\mathrm{C}$ & $\mathrm{m}$ & $R^{2}$ \\
\hline CT-V-1 & $\mathrm{V}$ & $\mathrm{T}$ & 10 & $7.51 \times 10^{-8}$ & 2.39 & 0.993 \\
CT-V-2 & $\mathrm{V}$ & $\mathrm{B}$ & 10 & $7.37 \times 10^{-8}$ & 2.39 & 0.997 \\
CT-V-3 & $\mathrm{V}$ & $\mathrm{B}$ & 10 & $8.34 \times 10^{-9}$ & 2.99 & 0.995 \\
CT-H-1 & $\mathrm{H}$ & $\mathrm{T}$ & 10 & $4.29 \times 10^{-9}$ & 3.11 & 0.996 \\
CT-H-2 & $\mathrm{H}$ & $\mathrm{B}$ & 10 & $3.37 \times 10^{-8}$ & 2.59 & 0.989 \\
CT-H-3 & $\mathrm{H}$ & $\mathrm{T}$ & 10 & $2.80 \times 10^{-9}$ & 3.28 & 0.991 \\
CT-V-4 & $\mathrm{V}$ & $\mathrm{B}$ & 11 & $6.64 \times 10^{-9}$ & 3.08 & 0.993 \\
CT-V-5 & $\mathrm{V}$ & $\mathrm{B}$ & 11 & $1.32 \times 10^{-8}$ & 2.86 & 0.995 \\
CT-V-6 & $\mathrm{V}$ & $\mathrm{B}$ & 11 & $9.09 \times 10^{-9}$ & 2.97 & 0.997 \\
CT-H-4 & $\mathrm{H}$ & $\mathrm{B}$ & 11 & $5.20 \times 10^{-8}$ & 2.49 & 0.995 \\
CT-H-5 & $\mathrm{H}$ & $\mathrm{B}$ & 11 & $3.94 \times 10^{-8}$ & 2.56 & 0.996 \\
CT-H-6 & $\mathrm{H}$ & $\mathrm{B}$ & 11 & $2.46 \times 10^{-8}$ & 2.72 & 0.997 \\
\hline
\end{tabular}

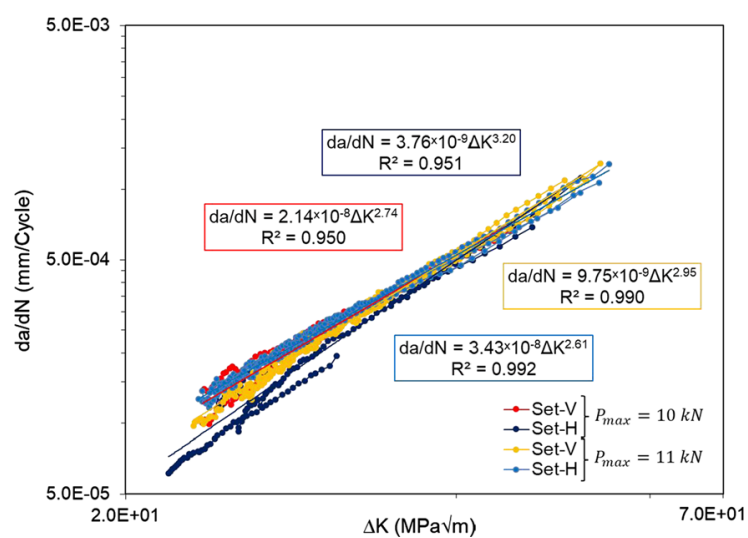

Fig. 6 The lines of best fit made to the fatigue crack growth data in the Paris region for different specimen orientations and load levels

Furthermore, the Paris law constants were determined for each set of specimens with the same orientation (i.e. vertical and horizontal) and under a given loading condition $\left(P_{\max }\right.$ of $10 \mathrm{kN}$ and $\left.11 \mathrm{kN}\right)$. The results obtained from the line of best fit (i.e. mean line) for each dataset are presented in Fig. 6 and summarised in Table 4. As seen in Fig. 6 and Table 4, the $R^{2}$ values are found to be slightly higher for specimens tested under $P_{\max }=11 \mathrm{kN}$, indicating less scatter in these datasets, compared to those tested at $P_{\max }=10 \mathrm{kN}$, which is consistent with observations made in Fig. 4. Lower values of $R^{2}$ for specimens tested under $P_{\max }=10 \mathrm{kN}$ suggests more scattered results. To further analyse the level of scatter in each of the obtained datasets, the upper bound trends were calculated based on +2 standard deviation (SD) by assuming the same slope as the mean line. The Power-law constants for the upper bound FCG trends (mean+2SD) in the Paris region for each of the four datasets are reported in Table 4.

The mean+2SD lines for four sets of experiments on different specimen orientations and load levels are plotted and compared with each other in Fig. 7. Also included in this figure are the BS7910 recommended fatigue crack growth trends (BS 7910 2015) (i.e. upper bound trends) for welded joints in air based on the simplified law and 2-stage law. From the figure it can be seen that all four lines describing the upper bound FCG behaviour of ER70S-6 WAAM specimens fall below the simplified and 2-stage FCG trends recommended in the BS7910 standard. This indicates that the FCG rates in ER70S-6 WAAM built components can be conservatively predicted by the recommended trends in the BS7910 standard. It can be seen in Fig. 7 that the upper bound FCG lines for the vertical specimens at $10 \mathrm{kN}$ and horizontal specimens at $11 \mathrm{kN}$ have similar slopes to the 2-stage law recommended in BS7910, while the other two datasets (i.e. horizontal specimens at $10 \mathrm{kN}$ and vertical specimens at $11 \mathrm{kN}$ ) have similar slopes to BS7910 simplified law.

Furthermore, the FCG data obtained from this study have been compared with the fatigue test data in air on $\mathrm{S} 355 \mathrm{G}+10 \mathrm{M}$ structural steel $\mathrm{C}(\mathrm{T})$ specimens extracted from the heat affected zone (HAZ) tested by Jacob et al. (2018) and S355G8+M steel C(T) specimens on 
HAZ and base metal (BM) tested by Mehmanparast et al. (2017); both sets of specimens have been prepared replicating the existing welds in offshore wind turbine monopile structures using the multi-pass butt-welding and no post-weld heat treatment was performed on the welded specimens. All tests have been conducted under similar loading conditions of $P_{\max }=10 \mathrm{kN}$, $5 \mathrm{~Hz}$ frequency and $R=0.1$, and the results are presented in Fig. 7. The comparison of the experimental data in this figure shows that the upper bound FCG trends from ER70S-6 WAAM specimens fall slightly above the experimental data band from S355G8+M $\mathrm{BM}$ specimens. Also seen in this figure is that the upper bound FCG rates in ER70S-6 WAAM specimens are on average around three and four times higher than S355G8+M and S355G+10M HAZ specimens, respectively. Knowing that S355G8+M and $\mathrm{S} 355 \mathrm{G}+10 \mathrm{M}$ are widely used in the fabrication of offshore structures, which are subjected to severe cyclic loading conditions during their lifespan (Igwemezie et al. 2019; Jacob et al. 2019; Jacob and Mehmanparast 2021), the comparison of results in Fig. 7 shows that the WAAM technology can be potentially employed in the fabrication of less critical components and parts of offshore structures using low carbon steel wires, though the fatigue crack growth rates are expected to be higher than the S355 weldments but still lower than the recommended FCG trends provided in the BS7910 standard.

\section{Fractography}

Upon completion of the FCG tests, post-mortem analysis was conducted on all specimens to evaluate the percentage of error in crack length estimations using the compliance technique. In order to do this, the tested specimens were initially soaked in liquid nitrogen for 10 minutes to increase the brittleness of the material and facilitate the fast fracture opening process with minimum plastic deformation. Examples of fracture surfaces are shown in Fig. 8 for different specimen orientations and loading conditions. As seen in Fig. 8a, three surface areas were identified on the fracture surface: (1) fatigue pre-cracking, (2) fatigue crack growth, and (3) fast fracture (i.e. specimen fracture opening). The crack extension was measured in the first two regions for all 12 specimens tested in this study. The fractography analysis of the tested specimens shows that the crack propagation regions are quite symmetric for each specimen, which confirms that perfect appropriate alignment was maintained during the FCG tests. It can be also observed that the macroscopic fatigue crack growth regions are very smooth for all specimen orientations without any evidence of significant defects or crack deviation from the straight line on the fracture surface.

The information on the key specimen dimensions, the machined crack length $a_{o}$, the crack length after pre-cracking process estimated using the compliance method $a_{i, p}$, the final crack length after FCG test estimated using the compliance method $a_{f, c}$, and the final crack length measured on the fracture surfaces using optical imaging $a_{f, o p}$, is summarised in Table 5. As seen in this table, the percentage of error between the estimated (using the compliance technique) and measured (using optical imaging on the fracture surface) final crack lengths is less than $2.2 \%$, confirming that the crack lengths were accurately estimated during FCG tests using the compliance technique.

In order to examine the FCG rate differences observed in Fig. 5, further microstructural analysis has been conducted on the broken-open specimens using a TESCAN VEGA 3 Scanning Electron Microscope (SEM) with high 5kx magnification and the results are presented in Fig. 9. Since the largest difference in FCG rates took place at lower $\Delta K$ values and became almost negligible towards the end of the tests, the microstructural analysis was performed on the area corresponding to the beginning of the test (approximately $2 \mathrm{~mm}$ ahead of the pre-cracked region). The fracture surface analysis on the horizontal specimen tested at $P_{\max }=10 \mathrm{kN}$ (Fig. 9a), revealed dimpled rupture characteristics and large secondary cracks, which is compelling evidence of the ductile fracture mechanism. On the other hand, the fracture surface of the vertical specimen tested at $P_{\max }=10 \mathrm{kN}$ (Fig. 9b) consists of nearly flat regions, in the absence of secondary cracks, where a relatively fast cleavage fracture occurs during the crack propagation process confirming the brittle fracture in the vertical specimen. Similar observations were reported by several researchers (Rafieazad et al. 2019, 2021; Xu et al. 2018). Based on the microstructural analysis, it can be concluded that the specimen orientation plays a significant role in microstructural deformation and subsequently the FCG behaviour of WAAM ER70S6 specimens, and the horizontal specimen orientation which requires a higher amount of energy for crack to propagate due to the ductile cracking mode, exhibits 
Table 4 Power-law constants for the mean curves and upper bound trends in the Paris region for different orientations and load levels

\begin{tabular}{|c|c|c|c|c|c|c|c|}
\hline \multirow[t]{2}{*}{ Datasets } & \multirow[t]{2}{*}{ Orientation } & \multirow{2}{*}{$P_{\max }(k N)$} & \multicolumn{3}{|l|}{ Mean } & \multicolumn{2}{|l|}{ Mean + 2SD } \\
\hline & & & $\bar{C}$ & $m$ & $R^{2}$ & $\bar{C}$ & $m$ \\
\hline Set-V & V & 10 & $2.14 \times 10^{-8}$ & 2.74 & 0.950 & $2.61 \times 10^{-8}$ & 2.74 \\
\hline Set-H & $\mathrm{H}$ & 10 & $3.76 \times 10^{-9}$ & 3.20 & 0.951 & $4.95 \times 10^{-9}$ & 3.20 \\
\hline Set-V & V & 11 & $9.75 \times 10^{-9}$ & 2.95 & 0.990 & $1.09 \times 10^{-8}$ & 2.95 \\
\hline Set-H & $\mathrm{H}$ & 11 & $3.43 \times 10^{-8}$ & 2.61 & 0.992 & $3.79 \times 10^{-8}$ & 2.61 \\
\hline
\end{tabular}

Fig. 7 Comparison of the upper bound fatigue crack growth trends on ER70S-6 WAAM specimens to BS7910 curves and literature data on S355
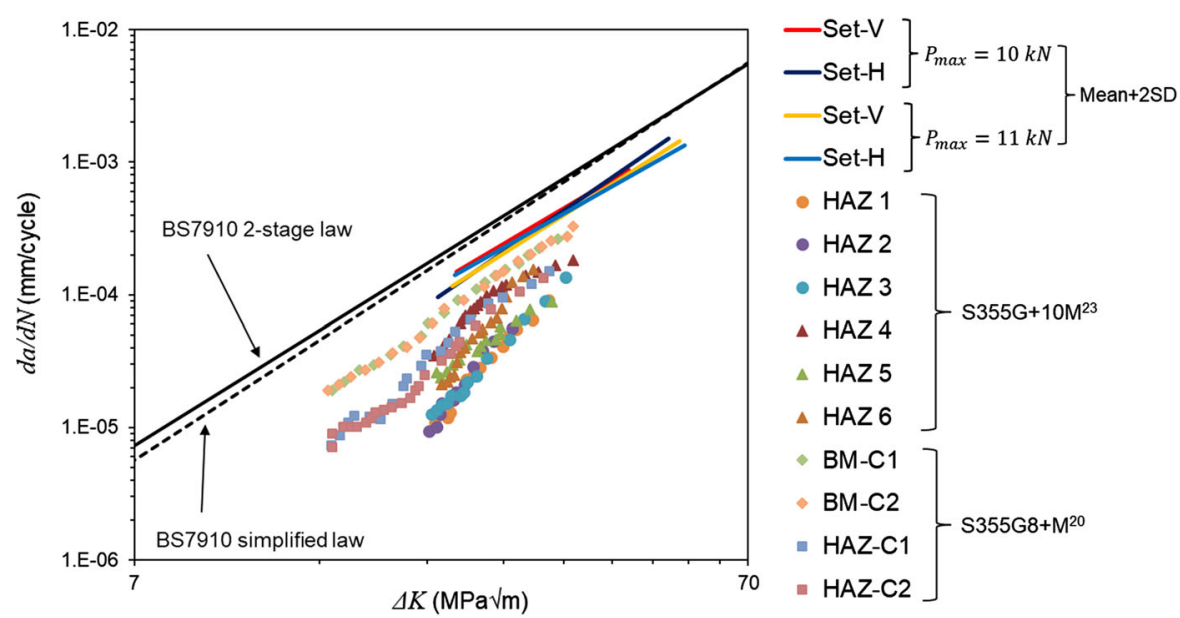

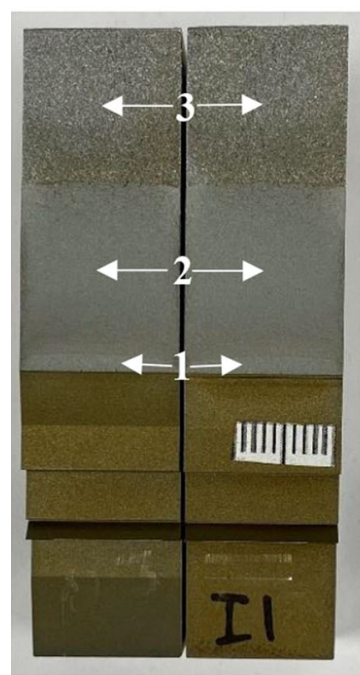

(a)

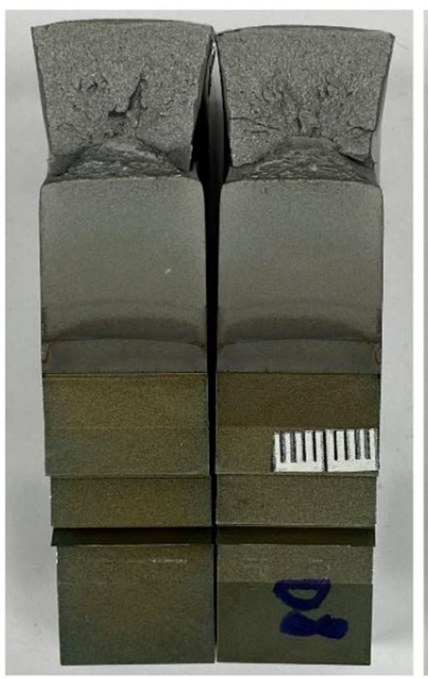

(b)

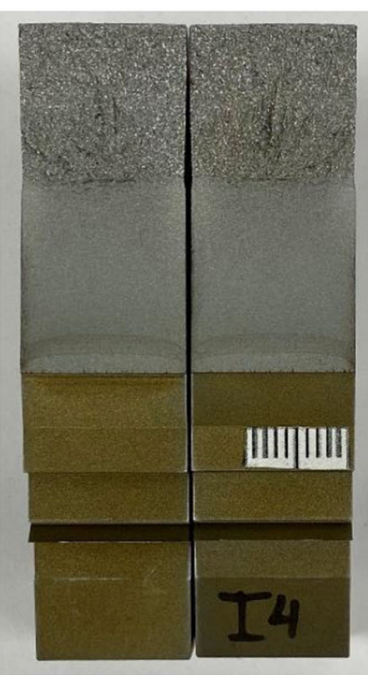

(c)

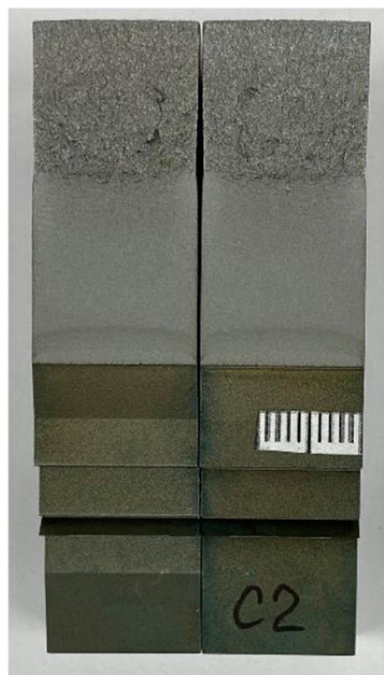

(d)

Fig. 8 Fracture surface of ER70S-6 WAAM specimens tested under $P_{m} a x=10 \mathrm{kN}$ : a CT-V-3 vertical, b CT-H-2 horizontal; and under $P_{m} a x=11 \mathrm{kN}$ : c CT-V-6 vertical, d CT-H-4 horizontal

a lower FCG rate compared to the vertical specimen tested under the same cyclic loading condition (see Fig. 5).
To examine the influence of plasticity on the FCG behaviour of specimens with different orientations, further microstructural analyses were conducted on the 
Table 5 Specimen dimensions, loading condition, initial and final crack lengths

\begin{tabular}{|c|c|c|c|c|c|c|c|c|}
\hline Specimen ID & $P_{\max }(\mathrm{kN})$ & $W(\mathrm{~mm})$ & $B(\mathrm{~mm})$ & $a_{0}(\mathrm{~mm})$ & $a_{i, p}(\mathrm{~mm})$ & $a_{f, c}(\mathrm{~mm})$ & $a_{f, o p}(\mathrm{~mm})$ & $\%$ error in $a_{f}$ \\
\hline CT-V-1 & 10 & 50.1 & 16.0 & 17.0 & 21.9 & 35.0 & 35.8 & 2.2 \\
\hline CT-V-2 & 10 & 50.0 & 16.1 & 17.1 & 23.2 & 35.0 & 34.7 & 0.8 \\
\hline CT-V-3 & 10 & 50.0 & 16.0 & 17.0 & 20.1 & 35.0 & 34.8 & 0.7 \\
\hline CT-H-1 & 10 & 50.0 & 16.0 & 17.2 & 19.7 & 35.0 & 34.9 & 0.2 \\
\hline CT-H-2 & 10 & 50.1 & 16.2 & 17.1 & 19.9 & 35.0 & 35.7 & 2.0 \\
\hline CT-H-3 & 10 & 50.0 & 16.1 & 17.0 & 19.5 & 35.0 & 35.0 & 0.2 \\
\hline CT-V-4 & 11 & 50.2 & 16.0 & 17.1 & 19.9 & 35.0 & 35.2 & 0.5 \\
\hline CT-V-5 & 11 & 50.0 & 16.2 & 17.0 & 20.1 & 35.0 & 35.3 & 0.7 \\
\hline CT-V-6 & 11 & 50.1 & 16.0 & 17.0 & 20.2 & 35.0 & 35.2 & 0.5 \\
\hline CT-H-4 & 11 & 50.1 & 16.0 & 17.0 & 20.3 & 35.0 & 35.4 & 1.0 \\
\hline CT-H-5 & 11 & 50.0 & 16.1 & 17.2 & 20.3 & 35.0 & 35.4 & 1.0 \\
\hline СТ-H-6 & 11 & 50.0 & 16.0 & 17.1 & 20.1 & 35.0 & 35.1 & 0.2 \\
\hline
\end{tabular}

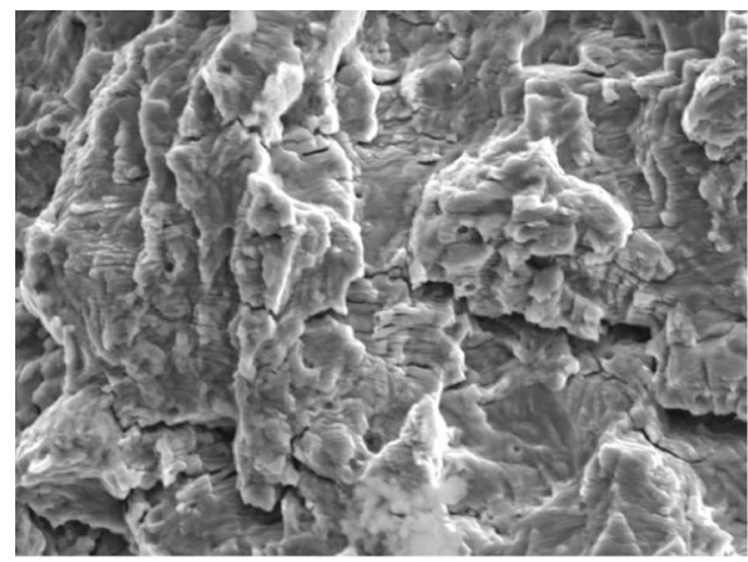

(a) horizontal, $P_{\max }=10 \mathrm{kN}$

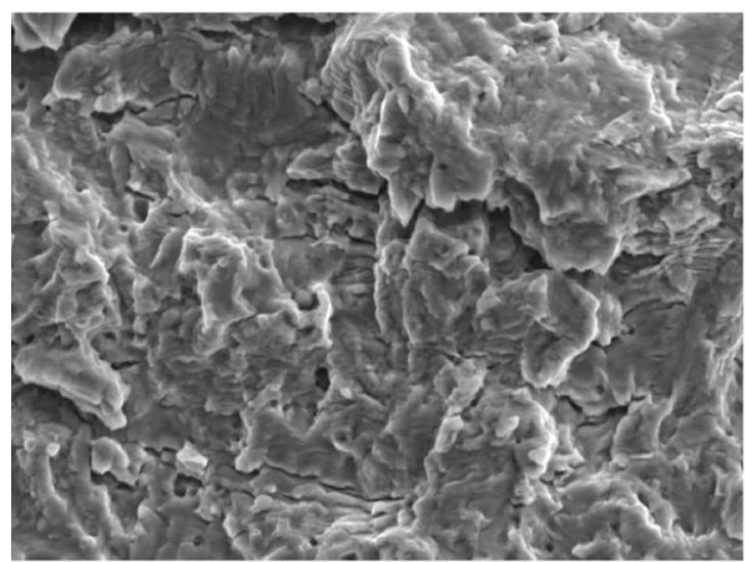

(c) horizontal, $P_{\max }=11 \mathrm{kN}$

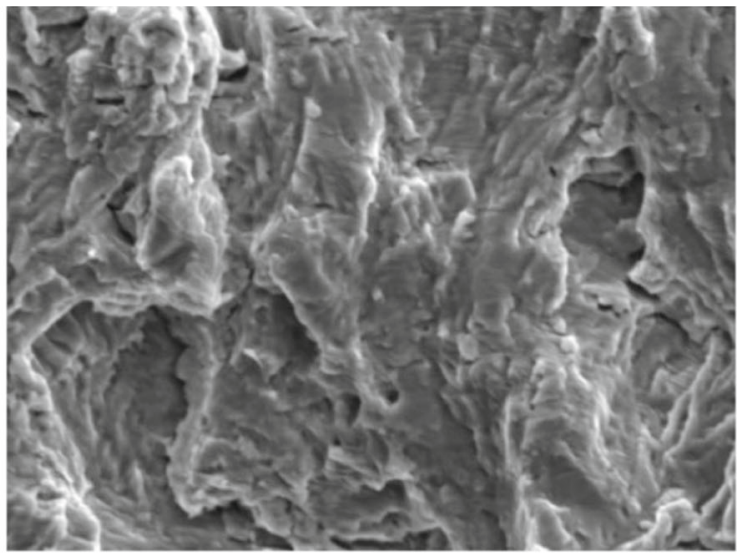

(b) vertical, $P_{\max }=10 \mathrm{kN}$

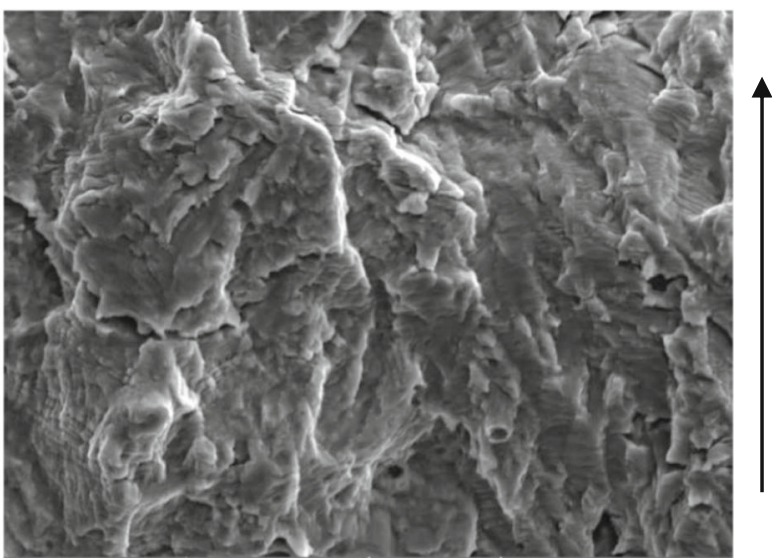

(d) vertical, $P_{\max }=11 \mathrm{kN}$

Fig. 9 Fracture surface of the FCG specimens with $5.0 \mathrm{kx}$ magnification (arrow on the right shows the crack propagation direction) 


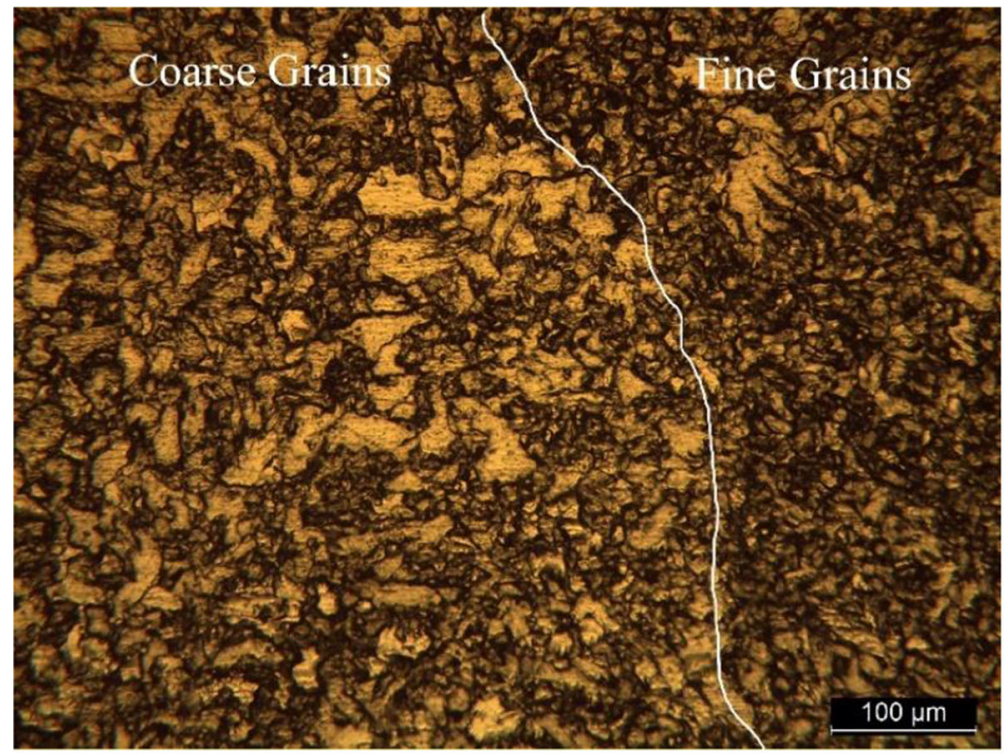

(a)

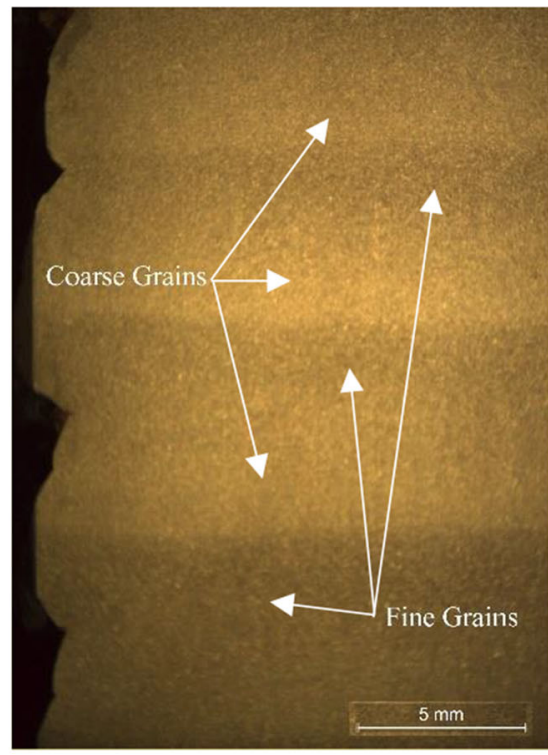

(b)

Fig. 10 Optical microscopy analysis of a vertical specimen revealing (a) grains size (b) different WAAM layers

horizontal and vertical specimens tested at $P_{\max }=$ $11 \mathrm{kN}$ (see Fig. 9c and d). Comparison of the microstructural deformation in the horizontal specimens tested at $P_{\max }=10 \mathrm{kN}$ in Fig. $9 \mathrm{a}$ and at $P_{\max }=11 \mathrm{kN}$ in Fig. 9c shows that increasing the load level on this specimen orientation has resulted in shallower dimples and lower density of secondary cracks, indicating a less ductile fracture behaviour in the test conducted at a higher load. This means that in the horizontal specimen orientation, an increase in the cyclic load level leads to higher FCG rates, in the absence of significant plasticity effects, which is consistent with the FCG trends observed in Fig. 5. Comparison of the microstructural deformation in the vertical specimens tested at $P_{\max }=10 \mathrm{kN}$ in Fig. $9 \mathrm{~b}$ and at $P_{\max }=11 \mathrm{kN}$ in Fig. 9d shows that increasing the load on this specimen orientation results in dimpled features and small secondary cracks, as a result of plasticity, which would subsequently decrease the FCG rates. This observation is consistent with the results shown in Fig. 5 where the FCG rates in the vertical specimens tested at a higher load fall below or upon those obtained at a lower load. This confirms that under the cyclic loading conditions examined in this study the vertical specimens are more sensitive to plastic deformation, therefore an increase in the maximum fatigue load from 10 to $11 \mathrm{kN}$ reduces the FCG trend due to the formation of dimpled regions and secondary cracks which increase the resistance of the material to crack propagation.

The grain size is known to be an important microstructural characteristic that determines the mechanical behaviour of the metal (Rafieazad et al. 2021). In order to analyse the grain size distribution in the test specimens, a vertical slice of the WAAM wall was examined under the optical microscope and the results are shown in Fig. 10a and b. As seen in this figure, the grain coarsening feature in the HAZ of the previously deposited WAAM layer is clearly visible, whereas the area of the melt pool consists of relatively smaller grains. Knowing that the nature of the WAAM process is layer-by-layer deposition, depositing every new layer reheats the previous layer and the temperature increase in the previously solidified layer initiates the grain boundaries migration and causes grain growth near each melt pool boundary. These microstructural inhomogeneities in the WAAM manufactured components cause anisotropic mechanical properties. According to Fig. 10b, the mechanical properties of the vertical specimens could change up to four times during the FCG test, as the crack propagated for around $15 \mathrm{~mm}$, hence through multiple WAAM layers. It was previously suggested by Rafieazad et al. (2019) that the presence of the coarse grains in the HAZ could be one of the main weakening mechanisms in WAAM ER70S- 
6 alloy, which deteriorates the ductility of the material. Thus, in addition to the microstructural deformation characteristics, the variation in mechanical properties could also influence the FCG behaviour in vertical specimens at different applied load levels. Further examination of the changes in mechanical properties in vertical samples will be conducted in future work.

\section{Conclusions}

Fatigue crack growth tests were conducted in air on standard tension $\mathrm{C}(\mathrm{T})$ specimens extracted from ER70S-6 WAAM built walls. All tests were performed at room temperature, with $R=0.1$, frequency of $5 \mathrm{~Hz}$, at two different load levels of $P_{\max }=10 \mathrm{kN}$ and 11 $\mathrm{kN}$. The following conclusions and observations have been made from this study:

- The specimen extraction location with respect to the WAAM wall does not have any major effect on the FCG behaviour of specimens.

- Depending on the applied load level, different specimen orientations may introduce some variation in the test results. Under $P_{\max }=10 \mathrm{kN}$ the horizontal specimens showed a twice longer fatigue life, while vertical specimens exhibited a 1.3 times longer fatigue life under $11 \mathrm{kN}$.

- The lowest fatigue crack growth rate was observed in horizontal specimens tested at $P_{\max }=10 \mathrm{kN}$ and the highest in horizontal specimens tested under $P_{\max }=11 \mathrm{kN}$.

- The mean+2SD lines obtained from the fatigue crack growth test data on ER70S-6 WAAM specimens with different orientations and tested at different load levels fall below the recommended trends of the BS7910 standard.

- Comparison of the FCG data on ER70S-6 WAAM specimens with HAZ S355 steels, shows that higher fatigue crack growth rates are observed in WAAM built components, while the results fall close to the upper bound data band on S355G8+M base metal.

- The fractography analysis confirmed the accuracy of the compliance method for crack length estimation in WAAM built samples.

- Analysis of the fracture surfaces showed that the microstructural deformation mechanism significantly depends on the specimen orientation and is found to be ductile in horizontal and brittle in vertical specimens tested at $P_{\max }=10 \mathrm{kN}$.
- The vertical specimens are more sensitive to material inhomogeneity and also plasticity effects at higher load levels, which would cause dimpled ductile fracture regions and reduced FCG trends.

Acknowledgements This work was supported by Grant EP/L016303/1 for Cranfield, Oxford and Strathclyde Universities' Centre for Doctoral Training in Renewable Energy Marine Structures - REMS CDT (http://www.rems-cdt.ac.uk/) from the UK Engineering and Physical Sciences Research Council (EPSRC).

Open Access This article is licensed under a Creative Commons Attribution 4.0 International License, which permits use, sharing, adaptation, distribution and reproduction in any medium or format, as long as you give appropriate credit to the original author(s) and the source, provide a link to the Creative Commons licence, and indicate if changes were made. The images or other third party material in this article are included in the article's Creative Commons licence, unless indicated otherwise in a credit line to the material. If material is not included in the article's Creative Commons licence and your intended use is not permitted by statutory regulation or exceeds the permitted use, you will need to obtain permission directly from the copyright holder. To view a copy of this licence, visit http://creativecommons.org/licenses/ by/4.0/.

\section{References}

American Society for Testing and Materials. ASTME-1820-11: standard test method for measurement of fracture toughness. Annu B ASTM Stand (2011) https://doi.org/10.1520/ E1820-18

Anderson TL (2005) Fracture mechanics: fundamentals and application. Taylor \& Francis Group, New York

ASTM E647-13. Standard Test Method for Measurement of Fatigue Crack Growth Rates. Am Soc Test Mater (2014) https://doi.org/10.1520/E0647-15E01.2

Brandl E, Baufeld B, Leyens C, Gault R (2010) Additive manufactured Ti-6A1-4V using welding wire: comparison of laser and arc beam deposition and evaluation with respect to aerospace material specifications. Phys Procedia 5:595606

BS 7910. BSI Standards Publication Guide to methods for assessing the acceptability of flaws in metallic structures. BSI Stand. Publ. 490 (2015)

Ding D, Pan Z, Cuiuri D, Li H (2015) Wire-feed additive manufacturing of metal components: technologies, developments and future interests. Int J Adv Manuf Technol 81:465-481

ER70S-6 - Weld WireWeld Wire. http://www.weldwire.net/ weld_products/ww70s-6/

Ermakova A, Mehmanparast A, Ganguly S (2019) A review of present status and challenges of using additive manufacturing technology for offshore wind applications. Procedia Struct Integr 17:29-36

Ermakova A, Mehmanparast A, Ganguly S, Razavi J, Berto F (2020) Investigation of mechanical and fracture properties 
of wire and arc additively manufactured low carbon steel components. Theor Appl Fract Mech 109:102685

Gordon JV, Haden CV, Nied HF, Vinci RP, Harlow DG (2018) Fatigue crack growth anisotropy, texture and residual stress in austenitic steel made by wire and arc additive manufacturing. Mater Sci Eng A 724:431-438

Greitemeier D, Dalle Donne C, Syassen F, Eufinger J, Melz T (2016) Effect of surface roughness on fatigue performance of additive manufactured Ti-6Al-4V. Mater Sci Technol (United Kingdom) 32:629-634

Igwemezie V, Mehmanparast A, Kolios A (2019) Current trend in offshore wind energy sector and material requirements for fatigue resistance improvement in large wind turbine support structures-a review. Renew Sustain Energy Rev 101:181-196

Jacob A et al (2018) Residual stress measurements in offshore wind monopile weldments using neutron diffraction technique and contour method. Theor Appl Fract Mech 96:418427

Jacob A, Mehmanparast A (2021) Crack growth direction effects on corrosion-fatigue behaviour of offshore wind turbine steel weldments. Mar Struct 75:102881

Jacob A, Mehmanparast A, D’Urzo R, Kelleher J (2019) Experimental and numerical investigation of residual stress effects on fatigue crack growth behaviour of S355 steel weldments. Int J Fatigue 128:105196

Lincoln Electric Company, T. LINCOLN ®ER70S-6 Welding Positions Typical Applications. www.lincolnelectric.com

Martina F, Mehnen J, Williams SW, Colegrove P, Wang F (2012) Investigation of the benefits of plasma deposition for the additive layer manufacture of Ti-6Al-4V. J Mater Process Technol 212:1377-1386

Mehmanparast A, Brennan F, Tavares I (2017) Fatigue crack growth rates for offshore wind monopile weldments in air and seawater: SLIC inter-laboratory test results. Mater Des 114:494-504

Mild Steel Welding Alloy ER70S-6 (GMAW) (MIG) ER70S-6 (GMAW) (MIG) Mild Steel Alloy · AWS ER70S-6. www. mathesongas.com

Nezhadfar PD et al (2019) Fatigue crack growth behavior of additively manufactured 17-4 PH stainless steel: effects of build orientation and microstructure. Int J Fatigue 123:168179
Pegues J, Roach M, Scott Williamson R, Shamsaei N (2018) Surface roughness effects on the fatigue strength of additively manufactured Ti-6Al-4V. Int J Fatigue 116:543-552

Rafieazad M, Ghaffari M, Vahedi Nemani A, Nasiri A (2019) Microstructural evolution and mechanical properties of a low-carbon low-alloy steel produced by wire arc additive manufacturing. Int J Adv Manuf Technol 105:2121-2134

Rafieazad M, Nemani AV, Ghaffari M, Nasiri A (2021) On Microstructure and Mechanical Properties of a Low-Carbon Low-Alloy Steel Block Fabricated by Wire Arc Additive Manufacturing. J Mater Eng Perform. https://doi.org/10. 1007/s11665-021-05568-9

Wang F, Williams S, Rush M (2011) Morphology investigation on direct current pulsed gas tungsten arc welded additive layer manufactured Ti6A14V alloy. Int J Adv Manuf Technol 57:597-603

Williams SW et al (2015) Wire + Arc Additive Manufacturing. Mater Sci Technol 32:641-647

Xu X et al (2018) Microstructural evolution and mechanical properties of maraging steel produced by wire + arc additive manufacture process. Mater Charact 143:152-162

Zhang J, Wang X, Paddea S, Zhang X (2016) Fatigue crack propagation behaviour in wire + arc additive manufactured Ti6Al-4V: effects of microstructure and residual stress. Mater Des 90:551-561

Zhang X, Martina F, Ding J, Wang X, Williams SW (2017b) Fracture toughness and fatigue crack growth rate properties in wire + arc additive manufactured Ti-6Al-4V. Fatig Fract Eng Mater Struct 40:790-803

Zhang X, Martina F, Syed AK (2017a) Fatigue Crack Growth in Additive Manufactured Titanium: Residual stress control and life evaluation method development Corrosion fatigue: pit-to-cracking transition-experimental and numerical modelling View project "Modelling Applications of Additive Manuf. 7-9 https://doi.org/10.13140/RG.2.2.29032.16643

Publisher's Note Springer Nature remains neutral with regard to jurisdictional claims in published maps and institutional affiliations. 